\title{
Evidence Based Library and Information Practice
}

EBL 101

\section{Evidence Based Librarianship Backgrounder}

Su Cleyle

Associate University Librarian

Memorial University of Newfoundland

St. John's, Newfoundland, Canada

E-mail: scleyle@mun.ca

Julie McKenna

Deputy Library Director

Regina Public Library

Regina, Saskatchewan, Canada

Email: jmckenna@reginalibrary.ca

\section{Originally published in:}

Evidence Based Library and Information Practice, 3(3), 91-93.

https://ejournals.library.ualberta.ca/index.php/EBLIP/article/view/4061/3329

Received: 13 April 2008

Accepted: 17 June 2008

(a) 2016 Cleyle and McKenna. This is an Open Access article distributed under the terms of the Creative CommonsAttribution-Noncommercial-Share Alike License 4.0 International (http://creativecommons.org/licenses/by-nc$\underline{\mathrm{sa} / 4.0 /)}$, which permits unrestricted use, distribution, and reproduction in any medium, provided the original work is properly attributed, not used for commercial purposes, and, if transformed, the resulting work is redistributed under the same or similar license to this one.

Evidence Based Librarianship (EBL) is a means to improve the profession of librarianship by asking questions, finding, critically appraising and incorporating research evidence from library science (and other disciplines) into daily practice. It also involves encouraging librarians to conduct research (Koufogiannakis and Crumley, 112).
Welcome to EBL 101! This new column is designed to offer guidance into the workings of evidence based practice and answer that question: "How can I implement EBL in my library?" The intent is to offer short, simple columns on a variety of EBL topics allowing any librarian, regardless of library type or size, to practice evidence based librarianship. So let's get to it, shall we? 
Evidence based practice (EBP) is a term that we have all heard. Usually it is associated with the health professions and originated the area of clinical medicine. The medical profession forged the way for many professions to embrace evidence based practice (EBM.) Back in the 1990's, Canadian doctors sought to create an environment of lifelong learning and clinical practice that utilitized research to answer clinical questions.

There are 5 steps to evidence based medicine:

1. Formulate an answerable question.

2. Track down the best evidence

3. Critically appraise the evidence (i.e. find out how good it is).

4. Apply the evidence (integrate the results with clinical expertise and patient values).

5. Evaluate the effectiveness and efficiency of the process (to improve next time) (Glasziou 23).

As you can see the concept of EBM is a simple one - gather evidence to help with answering questions and helping patients. For the discipline of medicine, the body of evidence is rich in these areas and it is conceivable that most questions can be answered through use of existing research evidence. But even though the steps seem simple enough, a variety of skills are needed to ensure each step is completed properly. For example, asking the right question is crucial to finding the best evidence; evaluating the evidence is pivotal to determining the best course of action, and so on.

\section{Evidence Based Librarianship (EBL)}

Evidence based practice is a practical approach to finding answers to questions and for professionals to stay abreast of current trends and research. It is also a useful model for contributing to the body of evidence. But will this model work in a discipline that is not grounded in the research practices associated with the collection and use of empirical data? The social sciences research base is very different from that in the sciences. It is possible to apply the evidence based practice model to social science disciplines, including librarianship?

EBP, quite simply, can encompass original research and the evaluation and use of existing research. Koufogiannakis, Crumley, and Slater reviewed several content analysis reports and note the "the variation in the interpretation of what constitutes a 'research' article..." (Koufogiannakis, Crumley, and Slater 228). Of the 2664 articles reviewed from the 2001 publishing year, $30.3 \%$ were identified as research articles. This is a rate similar to previous content reviews for librarianship, although there are variations in scope and definition of what "constitutes a 'research' article". Clearly, the higher percentage of articles appearing in our professional literature is not research oriented.

Librarianship is not primarily comprised of scholars or researchers. It is comprised of practitioners and administrators. Thus, research has not necessarily made its way into our professional literature and our decision making processes. Many of us in the profession now recognize the need to formalize our research and our decision making processes to ensure that we base our decisions on the best possible evidence.

Based on the EBM model, the steps for EBL are similar:

1. Define problem

2. Find evidence

3. Appraise evidence

4. Apply results of appraisal

5. Evaluate change 
6. Redefine problem

(Booth and Brice, 2003)

The definition of the problem, or "the question", is pivotal to the entire process. The next EBL 101 column will focus on asking the right question.

\section{Works Cited}

Booth, Andrew and Anne Brice:

"Evidence Based Librarianship: The first Steps." 2nd International

Evidence Based Librarianship

Conference, Edmonton, Alberta,

Canada, June 2003. April, 2005

$<$ http://www.shef.ac.uk/scharr/eblib Lonf2003.htm>.
Glasziou, Paul. Evidence Based Medicine Workbook. London, GBR: BMJ Publishing Group, 2003.

August, 2008

<http://site.ebrary.com/lib/memorial Doc?id=10049688\&ppg=29>.

Koufogiannakis, Denise, and Ellen Crumley. "Evidence Based Librarianship" Feliciter, 3 (2002):

112-4.

Koufogiannakis, Denise, Ellen Crumley, and Linda Slater. "A Content Analysis of Librarianship Research." Journal of Information Science 30.3 (2004): 227-39. 